\title{
DIVERSIDADE, FITOSSANIDADE E ADEQUAÇÃO DA ARBORIZAÇÃO AO AMBIENTE URBANO EM UM BAIRRO NA CIDADE DE OURINHOS, SP, BRASIL
}

\author{
Carolina da Silva e Souza ${ }^{12}$, Pavel Dodonov ${ }^{3}$, Rafael Bécheri Cortez ${ }^{4}$
}

\section{RESUMO}

A arborização e áreas verdes presentes nas cidades realizam diversos serviços ambientais , tais como melhoria da qualidade do ar e do micro clima, melhoria da paisagem, manutenção do ciclo da água e fornecimento de alimentos e abrigo para a avifauna. Foram avaliadas as árvores do bairro urbano Vila Margarida na cidade de Ourinhos, SP, com a mensuração de três medidas morfométricas, do vigor e da adequação ao ambiente de todos os indivíduos arbóreos, assim como o tipo de poda. Foram constatadas 30 espécies de árvores, sendo que as 20 espécies mais abundantes representaram 97\% dos indivíduos; a abundância relativa de cada espécie foi descrita pelo modelo "log-series". Cerca de $40 \%$ das árvores estavam em conflito com redes de fiação elétrica e $62 \%$ das árvores apresentavam danos causados pelo homem e por fatores naturais. Concluiu-se que a arborização deste bairro é deficiente tanto em abundâncias relativas das espécies quanto em sua adequação ao ambiente urbano. Propõe-se que o poder público tenha uma participação mais ativa na arborização urbana visando corrigir os problemas encontrados. Também propõe-se que sejam desenvolvidas atividades educativas com a população.

Palavras-chave: Arborização; Poda; Fiação elétrica; Abundância relativa de espécies

\section{DIVERSITY, VIGOUR AND ADEQUACY OF THE ARBORIZATION TO THE URBAN ENVIRONMENT IN A NEIGHBORHOOD IN THE CITY OF OURINHOS, SP, BRAZIL}

\begin{abstract}
Street trees and green areas that occur in the cities promote diverse environmental services such as improving air quality and microclimate, improving the landscape, maintaining the water cycle and supplying food and shelter to the avifauna. Trees of the urban neighborhood of Vila Margarida in the city of Ourinhos, SP, were evaluated, with the measurement of three morphometric measures, of vigor, and of adequacy to the environment of all the arboreal individuals, along with the type of pruning. Thirty species of trees were found, with the 20 most abundant species accounting for $97 \%$ of the individuals; the relative species abundance was described by the "log-series" model. About $40 \%$ of the trees were in conflict with electric wiring and $62 \%$ of the trees presented damage caused by man or by natural factors. It was concluded that the arborization of this neighborhood is deficient both in relative abundance of species and in their adequacy to the urban environment. It is proposed that the city government engages more actively in the urban arborization in order to correct the problems that were found. It is also proposed that educational activities be developed with the population.
\end{abstract}

Key-words: Arborization; Pruning; Wiring; Relative species abundance.

\footnotetext{
${ }^{1}$ Bióloga, Doutoranda em Ecologia e Recursos Naturais, UFSCar, São Carlos, SP, carolinadasilvaesouza@yahoo.com.br

${ }^{2}$ Data recebimento: 08/08/2011 - Data de publicação: 15/12/2012

${ }^{3}$ Biólogo, Mestre Doutorando em Ecologia e Recursos Naturais, UFSCar, São Carlos, SP pdodonov@gmail.com

${ }^{4}$ Eng Agrônomo, ESALQ - USP , Piracicaba, SP, Esp. Gestão Ambiental e em Manejo Florestal, UFLA rbcortez@hotmail.com
} 


\section{INTRODUÇÃO}

O espaço urbano pode ser entendido como uma região composta por áreas edificadas (residências, comércio e indústrias), áreas destinadas à circulação da população (sistema rodoferroviário) e áreas livres de edificação (praças, quintais etc) (Guzzo, 1993). Por outro lado, ele também pode ser visto como um espaço que abrange diversos tipos de habitats, cada um com diferentes condições e, portanto, com diferente composição da fauna e flora; os habitats podem ser classificados em: tecnológico (paisagem biológica extensamente substituída por uma paisagem artificial), gardenesco (elementos biológicos funcionando apenas sob manejo constante), e ecológico (elementos biológicos funcionam de uma maneira natural) (Gilbert, 1991). Bolund e Hunhammar (1999) classificam os ecossistemas urbanos em: árvores de rua; parques ou gramados; florestas urbanas; área cultivada; áreas úmidas; lagos/mares; e rios. Os diferentes ecossistemas desempenham importantes funções para a população urbana, sendo que os de caráter estético, recreacional e cultural estão provavelmente entre os mais importantes, auxiliando na redução dos níveis de estresse da população (Bolund e Hunhammar, 1999). Entre as plantas que compõem a vegetação urbana, as árvores, em função de seu porte, são as plantas que produzem os maiores benefícios ambientais. Em locais de clima subtropical e tropical o sombreamento gerado pela presença de árvores é importante para a melhoria do clima nas cidades (Mascaró e Mascaró, 2005). Outro serviço ambiental importante prestado pela arborização urbana é a melhoria da qualidade do ar através da retenção de poeiras e poluentes pelas folhas, galhos e tronco. A redução da quantidade de particulados suspensos no ar pode atingir até $70 \%$ em ruas arborizadas (Bernatzky, 1983 apud Bolund e Hunhammar, 1999). As árvores também regulam o microclima urbano por meio da transpiração, processo que consome energia e, portanto reduz a temperatura, especialmente no verão; e podem também reduzir a velocidade do vento nas cidades (Bolund e Hunhammar, 1999). Por exemplo, na cidade de Tel Aviv (Israel), as árvores de rua reduziram a temperatura em aproximadamente $1^{\circ} \mathrm{C}$ nas ruas mais movimentadas, sendo que vegetação urbana em geral teve um efeito de resfriamento médio de $2,8{ }^{\circ} \mathrm{C}$; esse efeito é perceptível em até $100 \mathrm{~m}$ do sítio vegetado (Shashua-Bar e Hoffman, 2000).

A arborização das cidades é estratégica, quer como resposta às condições ambientais adversas, quer como elemento estético da paisagem urbana, buscando sua compatibilização com os projetos de renovação do tecido urbano (Milano e Dalcin, 2000). Para uma arborização eficiente, deve- se levar em conta as características de cada espécie e o seu comportamento nas condições edafoclimáticas a que serão expostas (Pivetta e Silva-Filho, 2002). Caso características como o porte da árvore não sejam levadas em conta durante a arborização, podem ocorrer confrontos de árvores com equipamentos urbanos tais como fiações elétricas, encanamentos, calhas, muros e postes de iluminação, entre outros, o que pode levar inclusive a danos e a manejo inadequado das próprias árvores. Por exemplo, no estado de Califórnia (EUA), onde em 2000 havia aproximadamente seis milhões de árvores, eram gastos 70 milhões de

Carolina da Silva e Souza et al. 
dólares para remediar conflitos entre o crescimento de raízes e as calçadas (McPherson, 2000). Conflitos entre árvores e redes elétricas também são bastante comuns, levando a custos com poda (Velasco et al., 2006) e até a riscos para trabalhadores municipais (Fiedler et al., 2006).

Outro fator importante é a velocidade de crescimento: árvores e arbustos de crescimento rápido, além de precisarem de mais tempo de exposição à luz, normalmente são mais frágeis e precisam de mais manutenção; assim, caso o principal objetivo da arborização seja o sombreamento, o ideal é combinar árvores de crescimento rápido com outras de crescimento mais lento (Mascaró e Mascaró, 2005).

Apesar das informações já expostas, estudos de ecologia em habitats urbanos têm sido negligenciados. As espécies usadas são escolhidas com base principalmente em fatores culturais, não ecológicos. (Gilbert, 1991). Além disso, grande parte das espécies usadas na arborização urbana é exótica. (Rocha et al. 2004) e a maior parte dos indivíduos pertence a poucas espécies (Rocha et al. 2004; Silva Filho 2002). Quando realizados, os estudos de ecologia em habitats urbanos, se limitam a falar da abundância relativa das espécies. Uma forma mais detalhada de descrição seria pelo uso de modelos de abundância desenvolvidos para a descrição de comunidades ecológicas (Magurran 1988). Estes modelos, além de descrever a variação nas abundâncias das diferentes espécies, permitem fazer inferências sobre os fatores responsáveis pela estruturação da comunidade (Magurran 1988), e podem também ser úteis para explicar a arborização urbana. Por exemplo, comunidades vegetais em ambientes mais extremos costumam ter uma ou poucas espécies muito dominantes, e serem descritas pelo modelo chamado série geométrica; já ambientes mais favoráveis, como o cerrado brasileiro, são mais frequentemente descritos pelo modelo log normal (Magurran 1988, Oliveira e Batalha 2005).

O grande desmatamento ocorrido para a formação do município e do crescimento urbano colocou as vegetações naturais em sério risco de extinção. Nas áreas urbanas as vegetações naturais são mais raras ainda e a arborização urbana se torna um grande elemento para possível conservação de espécies nativas e o mais completo elemento de mitigação de impactos ambientais e melhoria de qualidade de vida nas cidades.

A arborização da cidade possui poucos dados disponíveis, em conversas informais soube-se que os grandes plantios de Caesapinia pluviosa ocorreram nas décadas de 50 e 60 e cobriram a grande maioria da malha urbana.

Os resultados deste plantios foram usufruídos por várias décadas porém, neste mesmo período, os trabalhos de plantios e estudos da arborização em Ourinhos ficaram praticamente suspensos.

Assim, este estudo teve o objetivo de avaliar a arborização viária do bairro urbano Vila Margarida, na cidade de Ourinhos, SP, Brasil, quanto à diversidade, fitossanidade, manejo e tipos de poda. Foi feita também a aplicação de um modelo de abundância de espécies visando explicar o que influenciava a arborização. Finalmente, foi verificada a adequação da arborização ao ambiente urbano e a existência de conflitos entre as árvores e os outros elementos presentes no ambiente, como fiação elétrica e calçadas. O presente estudo, embora pequeno em área, é importante porque rompe com décadas de inércia em relação aos estudos da arborização urbana de Ourinhos. 


\section{MATERIAIS E MÉTODOS}

O estudo foi realizado na cidade de Ourinhos (SP), nas 19 quadras do bairro Vila Margarida (entre $22^{\circ} 58^{\prime} 15^{\prime \prime}$ e $22^{\circ} 58^{\prime} 29^{\prime \prime}$ S e $49^{\circ} 52^{\prime} 36^{\prime \prime}$ e $\left.49^{\circ} 52^{\prime} 49^{\prime \prime}\right)$. O perímetro do bairro é de 1,8 km, e nele foram percorridos $3.9 \mathrm{~km}$ de ruas. O bairro está localizado na microbacia hidrográfica do Córrego Chumbeadinha que é afluente direto do Rio Paranapanema. O interesse do trabalho em avaliar a arborização nesta área se deve ao fato da mesma ter sido uma das primeiras a ser urbanizada na cidade de Ourinhos e ter um grande número de residências em seu núcleo.

A altitude média da cidade de Ourinhos é de 483 m (IBGE, 2009). De acordo com o censo de 2005, a cidade possuía uma área de $296,1 \mathrm{~km}^{2}$, sendo 89,376 km² de área urbana, e uma população de 104.448 habitantes. O clima é Sub-Tropical com chuvas de verão (Cwa pela classificação de Köppen). A área do município era coberta em sua quase totalidade por floresta estacional semidecidual. Hoje restam apenas 250,38 ha desta floresta, 307,79 de floresta estacional semidecidual secundária e 312,87 de formações arbóreas e arbustivo-herbáceas em região de Várzea que, quando somados, representam somente 2,94\% do território do município (Instituto Florestal, 2005).

A coleta de dados foi feita nos meses de julho, agosto e setembro de 2006. Todas as árvores localizadas ao longo das ruas do bairro Vila Margarida foram identificadas em nível de espécie e caracterizadas quanto às variáveis abaixo. Cada espécie foi também classificada quanto à forma de vida (árvore, arbusto ou trepadeira). Os nomes científicos atualizados e as famílias de cada espécie foram obtidas das bases de dados Tropicos (Missouri Botanical Garden 2012) e The Plant List (The Plant List 2010) com o auxílio do sítio PlantMiner (Carvalho et al. 2010).

\section{Variáveis referentes às árvores}

As variáveis usadas para descrever as árvores foram baseadas em outros trabalhos. Os caracteres morfológicos das árvores foram avaliados através do agrupamento em classes de tamanho: para sua circunferência à altura do peito (três classes: menos de um metro, entre um e dois metros, e mais de dois metros de circunferência; mudas não foram incluídas), para altura (quatro classes: menos de quatro metros, entre quatro e oito metros, entre oito e doze metros, e acima de doze metros) (Rocha, et al. 2004) e diâmetro de copa (as mesmas classes da altura).

O tipo de poda foi classificado em sete tipos: (Meneghetti, 2003; Rocha, et al. 2004) ausência de poda: quando não há poda em árvores adultas; poda de formação, que conduz o crescimento da copa aumentando a distância entre a primeira bifurcação e o solo, usada para liberar espaço no passeio e na rua; poda de contenção, realizada na parte superior da árvore, visando impedir o contato dos galhos com a fiação e o crescimento lateral excessivo; poda topiária, que controla o crescimento apical e lateral; sendo normalmente feita em galhos jovens, não é considerada danosa, comumente usada com fins estéticos, alterando a forma da copa; poda drástica, que consiste na retirada de braços inteiros e na excessiva redução 
do tamanho da copa, resultando em danos permanentes à árvore; e podas em V e em L, que consistem na retirada de galhos que estejam em contato com a rede elétrica e interferindo na iluminação, alterando o formato da copa. As três últimas são muito executadas pela empresa de energia elétrica de Ourinhos.

A fitossanidade, que diz respeito à saúde da árvore, foi avaliada, levando em conta o vigor da copa, a integridade do tronco, o sistema radicular, quando visível, a existência de injúrias físicas, como lesões (causadas ou não por vandalismo), cavidades abertas e anelamento, além da presença de pragas e doenças como cupins, cochonilhas e fungos. Cada árvore foi avaliada em uma das cinco classes: saudável (sem lesões, tronco íntegro, sem parasitas), injuriada (com algumas lesões visíveis, mas que comprometam pouco a saúde da árvore), doente (com muitas lesões e/ou comprometida por parasitas), senescente (fraca ou em processo de degeneração supostamente por causa da idade) e morta (ausência de folhas e súber, tronco oco e completamente seco) (Meneghetti, 2003).

As espécies encontradas foram classificadas de acordo com sua forma de vida: Árvore (Arv), Arbusto (Arb) e Trepadeira (Tre); e de acordo com o porte: Pequeno (P), Médio (M), e grande (G).

\section{Variáveis referentes à relação das árvores com o ambiente urbano}

Para avaliar a relação entre as árvores e os instrumentos ambiente urbanos, foram considerados o estado da pavimentação (danificada, quando apresentava buracos ou rachaduras causados pelas raízes das árvores, ou íntegra), a presença de obstáculos (interferência entre árvores e objetos como postes de luz, ponto de ônibus, lixeiras, toldos, placas, garagens e varandas), e a relação com a fiação elétrica (se a árvore se encontrava ou não sob rede de alta ou baixa tensão ou cabos telefônicos) (Meneghetti, 2003; Silva, 2005).

Foi levada em conta a compatibilidade dos caracteres morfológicos da árvore, como o porte, e a sua fenologia, com as dimensões do espaço físico e a presença de rede elétrica. A área livre em torno da árvore também foi considerada, se era adequada ou não ao seu porte, ou seja, se era possível o crescimento perpendicular e paralelo das raízes, e se o solo era permeável ou não. As falhas (incluindo tocos de árvores cortadas) e covas vazias, assim como árvores mortas, também foram levantadas (Silva, 2005; Silva-Filho, 2002).

\section{Análise dos dados}

As falhas foram consideradas como representativas do número de árvores que poderiam ser plantadas. Sendo assim, propõe-se um índice de deficiência de arborização (IDEF):

$\mathrm{IDEF}=(\mathrm{N}$ adultos $+\mathrm{N}$ mudas $+\mathrm{N}$ falhas $) /(\mathrm{N}$ adultos $+\mathrm{N}$ mudas), onde $\mathrm{N}$ é o número total de indivíduos ou de locais disponíveis para plantio.

Quando não há falhas, este índice é igual a 1 ; quando o número de falhas é igual à quantidade de adultos e mudas, ele é igual a 2.

Este índice mostra se existem falhas na arborização da área estudada e a quantidade das falhas existentes, indicando o número de árvores que podem ser plantadas, enquanto outros índices indicam a presença de cobertura vegetal, como por exemplo a densidade arbórea por uma dada área (IDA) (Lima Neto, 2008).

A abundância relativa das espécies e das famílias encontradas foi analisada por gráficos de rankabundância para os quais foram encaixados os DIVERSIDADE, FITOSSANIDADE E ADEQUAÇÃO DA... 
quatro modelos principais (série geométrica, log series, log normal, broken stick) (Magurran, 1988), usando o programa Past (Hammer et al., 2001).
Tendo em vista que o encaixe para todos os modelos foi significativo, eles foram comparados visualmente.

\section{RESULTADOS E DISCUSSÃO}

Foram encontradas 292 árvores adultas, 37 mudas e 242 falhas. O índice de deficiência de arborização, portanto, foi de 1.74 .

De acordo com os valores de referência do IDEF, este valor de deficiência de arborização, obtido para a área do bairro indica a existência de falhas, e que seu número está próximo ao número de indivíduos adultos. Uma possível causa para isso é a ausência de um plano diretor que corrija e controle a manutenção das árvores.

Foram amostradas árvores de 30 espécies, sendo que as 20 espécies mais abundantes correspondem a 96,56\% dos indivíduos e oito espécies ocorreram com um único indivíduo (Tabela 1). Das 30 espécies, apenas 4 são nativas do Brasil: Licania tomentosa, Bougainvillea spectabilis, Tibouchina granulosa e Caesalpinia pluviosa. Três delas estão entre as 12 espécies mais abundantes.

A frequência das 20 espécies mais abundantes 95,6\% - foi maior do que a descrita por Rocha et al. (2004) para dois bairros do município de Nova Iguaçu, RJ, nos quais as 20 espécies mais abundantes representavam aproximadamente 90\% dos indivíduos. No entanto, a distribuição das espécies verificada foi mais equitativa do que a descrita para a cidade de Jaboticabal, SP, por Silva Filho et al. (2002), na qual apenas duas espécies foram encontradas com frequência maior que $10 \%$, e 16 espécies com frequência superior a $1 \%$. Mesmo assim, a proporção entre as espécies vai contra tanto às sugestões de Grey e Deneke (1978), que sugerem que nenhuma espécie deva exceder
$10 \%$ do total de árvores, quanto à observação de que espécies com abundância menor de $1 \%$ podem desconfigurar esteticamente o ambiente (Santos, 1994). A frequência relativa da espécie mais comum - 20,2\% - é similar entre este bairro de Ourinhos (20,21\%) e os dois bairros de Nova Iguaçu (21,61\% e 19,14\%) (Rocha et al., 2004).

O grande número de espécies e a baixa frequência de cada uma delas se deve ao fato de que a arborização não foi planejada e executada completamente pelo poder público, mas em parte, feita pelos moradores, conforme observado durante o estudo. Rocha et al. (2004) constatou a mesma condição em Nova Iguaçu, RJ; neste último caso, no entanto, as 20 espécies mais abundantes corresponderam a aproximadamente $90 \%$ dos indivíduos.

A distribuição em classes de tamanho das árvores (Tabela 2) foi diferente da encontrada por Rocha et al. (2004) para outra população de árvores de rua; na população estudada por estes autores, a primeira classe (menos de seis metros) era a mais abundante, e as classes seguintes (entre seis e sete metros, entre sete e oito metros, e acima de oito metros) eram menos frequentes do que a primeira..

A primeira classe de altura era composta principalmente por árvores jovens e que aparentemente não passaram por poda; no entanto, alguns indivíduos que entraram nessa classe podem ter sofrido algum tipo de poda, e tiveram portanto, seu tamanho original descaracterizado. Rocha et al. (2004), obteve sob rede aérea, 34\% dos indivíduos 
com altura inferior a 6,0 m, apresentando DAP superior a $10 \mathrm{~cm}$, indicando plantas na fase adulta que sofreram intervenções de poda, caracterizando a redução do seu porte.. Em relação à circunferência à altura do peito (CAP), a primeira classe de CAP, e também a mais abundante, representa a grande quantidade de árvores de pequeno porte adultas, tais como Schinus molle e Murraya paniculata, e de arbustos e trepadeiras. Algumas árvores jovens de espécies de grande porte (mas não árvores adultas podadas), como Ficus sp. e L. tomentosa, também entraram nesta classe.

TABELA 1 - Árvores de rua de um bairro em Ourinhos, SP. N: número de indivíduos; Freq: frequência relativa, em porcentagem; Forma: forma de vida (Arv: árvore; Arb: arbusto; Tre: trepadeira); Porte: o porte da espécie quando adulta (P: pequeno; M: médio; G: grande).

\begin{tabular}{|c|c|c|c|c|c|}
\hline \multirow[b]{2}{*}{$\begin{array}{l}\text { Família } \\
\text { Family }\end{array}$} & \multirow[b]{2}{*}{$\begin{array}{l}\text { Espécie } \\
\text { Espécie }\end{array}$} & & & & \\
\hline & & $\mathbf{N}$ & Freq & Forma & Porte \\
\hline Fabaceae & Caesalpinia pluviosa (DC.) & 59 & 20.21 & Arv & G \\
\hline Magnoliaceae & Magnolia champaca ((L.) Baill. ex Pierre) & 32 & 10.96 & Arv & M \\
\hline Moraceae & Ficus sp (L.) & 32 & 10.96 & Arv & G \\
\hline Chrysobalanaceae & Licania tomentosa ((Benth.) Fritsch.) & 31 & 10.62 & Arv & M \\
\hline Anacardiaceae & Schinus molle (L.) & 17 & 5.82 & Arv & $\mathrm{P}$ \\
\hline Malvaceae & Pachira aquatica (Aubl.) & 16 & 5.48 & Arv & G \\
\hline Rutaceae & Murraya paniculata ((L.) Jack) & 14 & 4.79 & Arv & $\mathrm{P}$ \\
\hline Combretaceae & $\begin{array}{l}\text { Terminalia catappa (L.) } \\
\text { Nectandra angustifolia ((Schrad.) Nees \& }\end{array}$ & 11 & 3.77 & Arv & M \\
\hline Lauraceae & Mart.) & 11 & 3.77 & Arv & M \\
\hline Moraceae & Ficus benjamina (L.) var. variegata & 10 & 3.42 & Arv & G \\
\hline Melastomataceae & Tibouchina granulosa ((Desr.) Cogn.) & 9 & 3.08 & Arv & $\mathrm{P}$ \\
\hline Oleaceae & Ligustrum lucidum W. T. Aiton & 9 & 3.08 & Arv & M \\
\hline Fabaceae & Bauhinia variegata (L.) & 7 & 2.39 & Arv & M \\
\hline Verbenaceae & Duranta erecta (L.) & 6 & 2.05 & Arb & $\mathrm{P}$ \\
\hline Myrtaceae & Psidium guajava (L.) & 3 & 1.03 & Arv & $\mathrm{P}$ \\
\hline Apocynaceae & Nerium oleander (L.) & 3 & 1.03 & Arv & $\mathrm{P}$ \\
\hline Proteaceae & Grevillea robusta (A.Cunn. ex R.Br.) & 3 & 1.03 & Arv & G \\
\hline Malvaceae & Hibiscus roseus (Thore) & 3 & 1.03 & Arv & M \\
\hline Malpighiaceae & Malpighia glabra (L.) & 2 & 0.68 & Arb & $\mathrm{P}$ \\
\hline Lamiaceae & Rosmarinus officinalis (L.) & 2 & 0.68 & Arb & $\mathrm{P}$ \\
\hline Nyctaginaceae & Bougainvillea spectabilis (Willd.) & 2 & 0.68 & Tre & $\mathrm{P}$ \\
\hline Rutaceae & Citrus sp. (L.) & 2 & 0.68 & Arv & $\mathrm{P}$ \\
\hline Rutaceae & Citrus aurantium (L.) & 1 & 0.34 & Arv & M \\
\hline Bignoniaceae & Spathodea campanulata (P.Beauv.) & 1 & 0.34 & Arv & G \\
\hline Rosaceae & Rosa gallica (L.) & 1 & 0.34 & Arb & $\mathrm{P}$ \\
\hline Moraceae & Artocarpus heterophyllus (Lam.) & 1 & 0.34 & Arv & G \\
\hline Anacardiaceae & Mangifera indica (L.) & 1 & 0.34 & Arv & G \\
\hline Euphorbiaceae & Euphorbia pulcherrima (Willd. ex Klotzsch) & 1 & 0.34 & Tre & $\mathrm{P}$ \\
\hline Annonaceae & Annona squamosa (L.) & 1 & 0.34 & Arv & M \\
\hline Bignoniaceae & Tecoma stans ((L.) Juss. ex Kunth) & 1 & 0.34 & Arv & $\mathrm{P}$ \\
\hline
\end{tabular}


TABELA 2 - Distribuição das árvores de rua de um bairro de Ourinhos (SP) em classes de altura, circunferência à altura do peito $(1,30 \mathrm{~m})$ e diâmetro de copa. Os intervalos de classe estão em metros, as freqüências estão em porcentagem.

\begin{tabular}{|c|c|c|c|c|c|}
\hline \multicolumn{2}{|c|}{ Altura (Hight) } & \multicolumn{2}{|c|}{$\begin{array}{l}\text { Circunferência } \\
\text { (Circumference) }\end{array}$} & \multicolumn{2}{|c|}{$\begin{array}{l}\text { Diâmetro de copa } \\
\text { (Canopy diameter) }\end{array}$} \\
\hline $\begin{array}{l}\text { Intervalo } \\
\text { de classe }\end{array}$ & $\begin{array}{l}\text { Freqüência } \\
\text { (Frequency) }\end{array}$ & $\begin{array}{l}\text { Intervalo } \\
\text { de classe }\end{array}$ & $\begin{array}{l}\text { Freqüência } \\
\text { (Frequency) }\end{array}$ & $\begin{array}{l}\text { Intervalo } \\
\text { de classe }\end{array}$ & $\begin{array}{l}\text { Freqüência } \\
\text { (Frequency) }\end{array}$ \\
\hline (Size & & (Size & & (Size & \\
\hline interval) & & interval) & & interval) & \\
\hline$<4$ & 20.55 & $<1$ & 54.11 & $<4$ & 36.15 \\
\hline $4-8$ & 59.93 & $1-2$ & 39.72 & $4-8$ & 45.27 \\
\hline 8-12 & 13.70 & $>2$ & 6.17 & 8-12 & 16.5 \\
\hline$>12$ & 5.82 & & & $>12$ & 2.08 \\
\hline
\end{tabular}

A maior parte das árvores da segunda classe eram indivíduos jovens ou adultos que passaram por poda drástica, tendo sua capacidade de exercer funções ambientais reduzidas. Nesta classe, havia um considerável número de indivíduos de $S$. molle, Ficus spp. jovens e com poda topiária, e Michelia champaca adultas. Na segunda classe de CAP estão incluídos indivíduos adultos de espécies arbóreas de médio porte como Terminalia catappa e indivíduos de grande porte adultos ou em desenvolvimento, como Pachira aquatica e Grevilea robusta.

A terceira classe de CAP era composta primariamente por indivíduos de médio porte bem desenvolvidos ou indivíduos de grande porte jovens ou adultos com podas drásticas. Entram nela indivíduos de espécies como T. catappa, Nectandra angustifolia, Ligustrum lucidum e C. pluviosa.

Tanto para altura quanto para diâmetro de copa a segunda classe foi a mais abundante.

A maior parte das árvores ficou abaixo de oito metros de altura (Tabela 2). Isso pode ser um fator favorável, já que árvores até seis metros teoricamente têm conflitos apenas com cabos de telefone, e as entre seis e onze metros de altura também poderiam ter conflito com redes de baixa tensão (Rocha et al., 2004).

É possível que a baixa quantidade de indivíduos na maior classe de altura se deva ao baixo número de árvores de grande porte plantadas e também à poda drástica realizada em alguns indivíduos altos. Nesta classe há o predomínio de C. pluviosa, em sua maioria adultas, e presença de Ficus sp., Mangifera indica e G. robusta.

A quantidade relativamente grande de indivíduos na primeira classe de diâmetro de copa pode ser explicada pela predominância de espécies de pequeno porte jovens como S. molle, M. paniculata e T. granulosa, e também pela presença de indivíduos jovens de espécies de porte maior. A poda, principalmente a drástica e a topiária, também podem reduzir o tamanho e modificar a forma da copa, como foi percebido para indivíduos de M.champaca, T. catappa e C. pluviosa.

Carolina da Silva e Souza et al. 
A maior quantidade de indivíduos com copa entre 4 e 12 m representa árvores de pequeno porte na fase adulta e que não tenham sofrido poda drástica ou poda topiária - por exemplo, M. paniculata e $T$. granulosa, e também árvores de médio porte jovens e adultas como $N$. angustifolia e Bauhinia variegata. Árvores adultas de grande porte, tais como Ficus sp. e C. pluviosa, também podem entrar nessa classe depois de sofrer poda.

As duas maiores classes de diâmetro de copa incluem apenas adultos de espécies de grande porte, como T. catappa, P. aquatica, C. pluviosa e $M$. indica, que não tenham sofrido poda drástica em suas copas. A maior parte das árvores eram adultas, mas com alguns indivíduos senescentes. Isso mostra que são poucas as árvores que chegam à fase adulta com a configuração original da copa. A baixa quantidade de árvores com copas largas também é prejudicial à função de resfriamento oferecida pelas árvores, já que tamanhos maiores de copa normalmente implicam que uma área maior será sombreada pela árvore, e o tamanho da área sombreada determina aproximadamente $80 \%$ do resfriamento oferecido pela árvore (Shashua-Bar e Hoffman, 2000).

A frequência dos tipos de poda (Figura 1) é relativamente regular, sendo que 25,7\% das árvores não sofreram nenhum tipo de poda. Nas árvores podadas, as podas topiária e drástica foram as mais comuns $(21,2$ e $25,6 \%$ das árvores, respectivamente), e as podas menos comuns foram as em $\mathrm{V}$ e em L (4,5 e 0,7\% das árvores). A porcentagem de árvores debaixo de rede elétrica foi de 38,7\%, o que condiz com a quantidade de indivíduos apresentando poda drástica, de contenção, em V ou em L, representadas por 40,4\% das árvores. Conflito com outros obstáculos (placas de trânsito, lixeiras, marquises, toldos etc) esteve presente em $18,7 \%$ das árvores.

GRAFICO 1 - Frequência dos diferentes tipos de poda nas árvores de rua em um bairro de Ourinhos, SP.

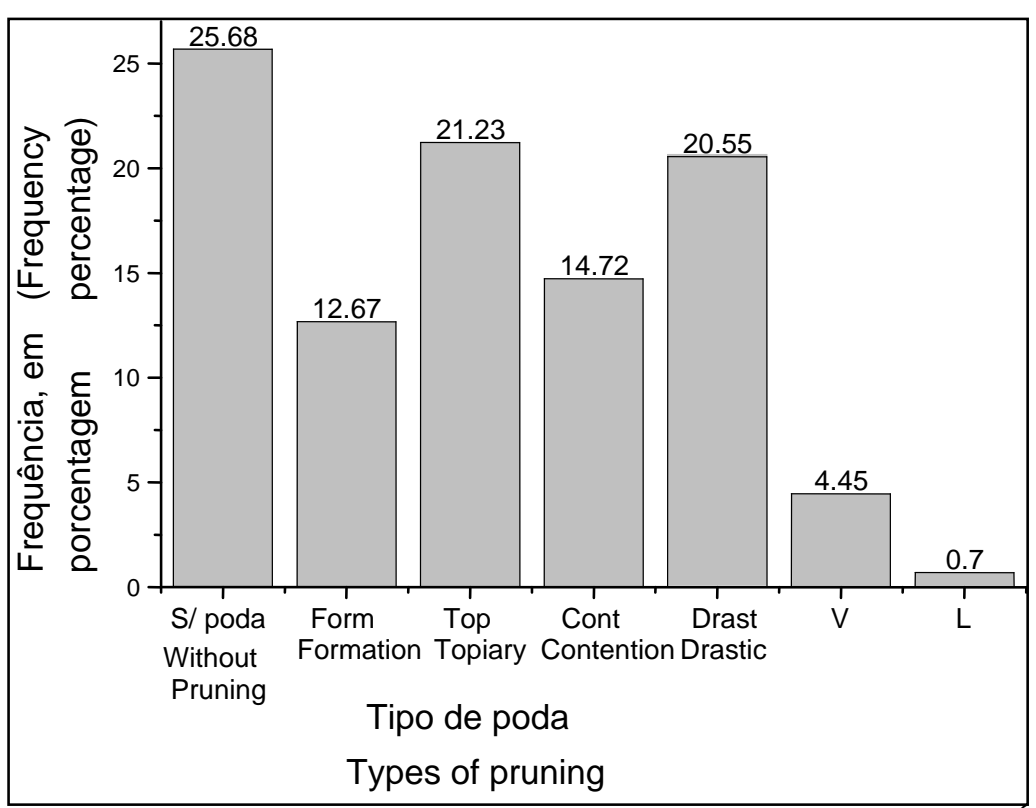
Esquerda para direita: sem poda; poda de formação; poda de topiaria; poda de contenção; poda drástica; poda em V; e poda em L.

A relativamente grande quantidade de árvores não podadas pode estar relacionada ao grande número de árvores jovens e de árvores adultas que não estão sob fiação elétrica ou em conflito com algum outro tipo de obstáculo. Por outro lado, a grande frequência de poda drástica entre as árvores podadas pode estar relacionada com o predomínio de espécies de grande porte como $C$.

pluviosa e Ficus sp. em contato com fiação aérea e outros obstáculos. Arvores que sofreram poda drástica eram mais propensas a apresentar lesões, descascamento excessivo e certa suscetibilidade a pragas como cupins ou cochonilhas.

DIVERSIDADE, FITOSSANIDADE E ADEQUAÇÃO DA... 
A poda de formação foi encontrada em espécies como L. lucidum, T. granulosa e M. paniculata. Neste tipo de poda não detectamos nenhum dano às plantas.

A poda topiária, usada para fins estéticos, foi encontrada especialmente em $M$. champaca (médio porte), Ficus sp. e Ficus benjamina var. variegata (grande porte). É o tipo de poda menos danoso, já que é aplicada normalmente em ramos jovens; no entanto, foi observado que, por atingir toda a copa, a poda topiária altera totalmente o formato das árvores, às vezes reduzindo a copa pela metade.

$\mathrm{A}$ poda em $\mathrm{V}$ foi relacionada à presença de espécies de grande porte, como $L$. tomentosa adulta e $C$. pluviosa jovem e adulta. Esse tipo de poda, além de desconfigurar a geometria da copa, pode enfraquecer a árvore a ponto de aumentar a possibilidade de queda de galhos inteiros, pela ação do vento e da chuva. A poda em L foi encontrada em indivíduos de C. pluviosa. Esse tipo de poda faz com que a árvore fique pendente para um único lado. Foram observadas lesões e fendas nas regiões cortadas, estas lesões podem levar a planta a um progressivo enfraquecimento e a um desequilíbrio entre a copa e o fuste.

Deste modo, vemos que alguns tipos de poda, principalmente a drástica, a em V e em L, são prejudicais à saúde da planta. Isso condiz com Velasco (2003), que relacionou problemas fitossanitários à execução de podas, verificando que apenas árvores podadas apresentaram parasitas ou fitófagos em Maringá - PR e Belo Horizonte - MG; neste último caso, doenças e parasitismo estavam mais associados as podas irregulares ou mal realizadas.
Neste estudo, 38,6\% das árvores estavam debaixo de fiação elétrica. De acordo com Velasco et al. (2006), a poda, especialmente a drástica, não é a única solução para conflitos entre rede elétrica e árvores urbanas: quando o contato é relativamente pequeno, a rede elétrica poderia ser transformada em rede compacta protegida, a qual requer menos manutenção e é menos sujeita a entrar em curto circuito em caso de contato com árvores. Embora a poda continue sendo feita anualmente, com a rede compacta protegida, o tipo de poda pode ser diferente, danificando menos a árvore. Embora o custo da poda não mude com o tipo de rede, o custo geral da manutenção da rede compacta é cerca de seis vezes menos do que o da rede convencional (Velasco et al., 2006). A mudança no tipo e intensidade de poda também poderia ser favorável aos trabalhadores, já que a poda com motosserra envolvendo escalada de árvores e a operação perto de redes elétricas foram consideradas as atividades mais perigosas pelos trabalhadores de poda em Brasília, DF (Fiedler et al., 2006).

A Figura 2 mostra o gráfico de rank-abundância construído a partir do número de indivíduos de cada espécie. O modelo que apresentou melhor encaixe foi o log-series $(p=0,99)$. Em ecossistemas naturais este modelo costuma ser encontrado quando um ou poucos fatores determinam a ecologia da comunidade. (Magurran, 1988). Acreditamos que essa explicação também é aplicável às árvores de rua, pois a sua distribuição é determinada essencialmente pelo fator cultural e pela capacidade de sobreviver no ambiente urbano (Gilbert, 1991).

GRAFICO 2 - Gráfico de rank-abundância das árvores de rua em um bairro de Ourinhos, SP - A linha representa o modelo log-series. 


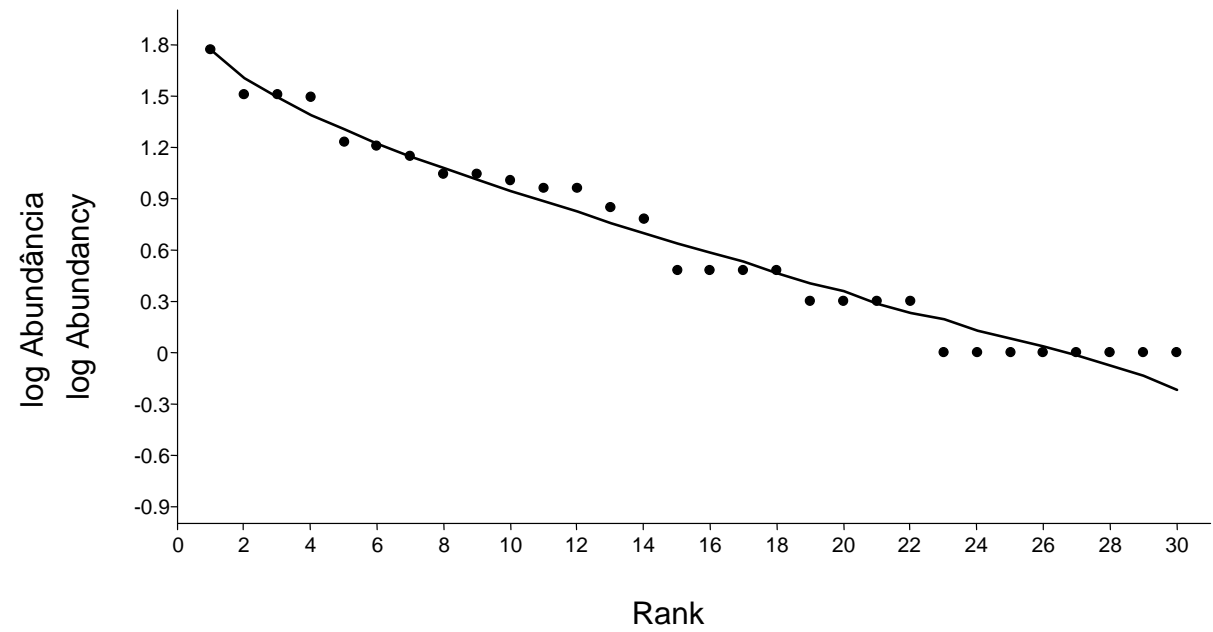

Com relação à adequação ao espaço físico, 63\% dos indivíduos estavam com área livre adequada, ou seja, com dimensões compatíveis da área livre com a base e o sistema radicular do indivíduo adulto, fornecendo a este, espaço e condições, como exposição do solo, necessários ao seu desenvolvimento. A área livre deve ter pelo menos60 centímetros de seção - superfície suficiente para permitir infiltração da água da chuva e aeração do solo, assim como possibilitar adubações futuras (Arborização Urbana Viária, 2008). De forma similar, apenas 23,9\% dos passeios estavam danificados pelas árvores. Apenas 35,3\% dos indivíduos se mostraram compatíveis com o ambiente, contra os 64,7\% incompatíveis.

Quanto à fitossanidade, 28,1\% das árvores se mostraram vigorosas, 52,1\% injuriadas, 8,2\% doentes, 11,3\% senescentes, e uma única árvore morta (correspondendo a 0,35\%). C.pluviosa foi a mais frequente entre as árvores injuriadas e senescentes. Entre as consideradas doentes, alguns indivíduos de $N$. angustifolia apresentaram fungos em seus galhos e folhas. C.pluviosa também esteve entre os indivíduos considerados doentes, devido ao ataque por cupins.
Passeios danificados, neste estudo, estavam relacionados principalmente com espécies de grande ou médio porte com sistema radicular superficial ou misto, como C. pluviosa e $T$. catappa. De acordo com Mascaró e Mascaró (2005), árvores de grande porte e com sistema radicular superficial devem ser evitadas na arborização, para evitar danos aos passeios. A seleção das espécies deve ser dimensionada adequadamente para o seu entorno pois desta forma são evitados problemas urbanos, além reduzir as intervenções de contenção de raízes e copas que muitas vezes prejudicam as plantas.

A compatibilidade entre o espaço físico e a espécie selecionada está diretamente relacionada com características do indivíduo como o porte, aspectos reprodutivos como floração e frutificação. Neste estudo, mais de $60 \%$ dos indivíduos se mostraram incompatíveis com o espaço físico, indicando que estes fatores aparentemente não foram levados em consideração.

A grande quantidade de árvores vigorosas pode estar relacionada à presença de indivíduos jovens ou adultos que não sofreram poda drástica. As árvores injuriadas apresentaram algum tipo de poda DIVERSIDADE, FITOSSANIDADE E ADEQUAÇÃO DA... 
ou dano como pregos, escritas e descascamento; entretanto as flores, frutos e folhas estavam saudáveis.
Indivíduos classificados como doentes foram aqueles que apresentavam injúrias em excesso, anelamentos, perda intensa de súber, fendas por todo o tronco e/ou queda espontânea de galhos.

\section{CONCLUSÕES}

A arborização do bairro estudado é deficiente de acordo com a quantidade de mudas presentes e da grande quantidade de falhas encontradas. Esta observação é confirmada pelo alto índice de deficiência de arborização encontrado. Grande parte das árvores estava em condições de fitossanidade abaixo do ideal e/ou em conflito com elementos do ambiente urbano, assim, as podas, drástica, em V e em $\mathrm{L}$ foram as mais prejudiciais, comprometendo o desenvolvimento e o desempenho desses indivíduos quanto às funções ambientais.

O uso de espécies exóticas na arborização é muito intenso apesar da grande diversidade de espécies encontradas no Brasil e da necessidade de se usar a arborização urbana como forma de preservação de espécies nativas fora de seus locais de origem.

Concluiu-se que a arborização do bairro de Vila Margarida, Ourinhos, SP apresenta uma enorme gama de erros que dizem respeito ao manejo e planejamento. Um novo plantio pode ser necessário para corrigir suas falhas. Percebe-se também que a arborização, apesar dos seus inúmeros e incontestáveis benefícios, não pertence ao planejamento principal das cidades, precisando se adaptar, por exemplo a calçadas estreitas, presença de tubulação e fiações elétricas que restringem a seleção das espécies e/ou imprimem uma pressão negativa ao desenvolvimento destas plantas.

\section{REFERÊNCIAS BIBLIOGRÁFICAS}

ARBORIZAÇÃo URBANA VIÁRIA. Aspectos de planejamento, implantação e manejo. Companhia Paulista de Luz e Força - CPFL, 2008. Disponível em: http://www.cpfl.com.br/Portals/0/pdf/Guia Meio Ambiente.pdf> Acesso em 20 abril 2009.

BOLUND, P.; HUNHAMMAR, S. Ecosystem services in urban areas. Ecological Economics,v. 29, p. 293-301, 1999.

BRASIL. IBGE - INSTITUTO BRASILEIRO DE GEOGRAFIA E ESTATÍSTICA, Disponível

em: <http://www.ibge.hpg.gov.br> Acesso em 8 de agosto de 2009.

CARVAlHO, G. H.; CiAnCiARUSO, M. V.; BATAlHA, M. A. Plantminer: a web tool for gathering plant species taxonomic information. Environmental Modelling \& Software, v. 25, p. 815-816, 2010.

FIEDLER, N. C.; SONE, E. H.; VALE, A. T. JUVÊNCIO, J. F.; MINETTE, L. J. Avaliação dos riscos de acidentes em atividades de poda de árvores na arborização urbana do Distrito Federal. Rev. Árvore, Viçosa, v. 30, n. 2, p. 223-233, 2006.

GILBERT, O. L. The ecology of urban habitats. London: Chapman \& Hall, 1991.

GREY, G.W.; DENEKE, F.J. Urban forestry. New York, John Wiley, 1978, 279p.

GUZZO, P. Alterações ambientais em áreas urbanas, planejamento e legislação ambiental. Anais do Seminário Latino Americano de Planejamento Urbano, Campo Grande, MS. 1993. 
HAMMER, Ø.; HARPER, D. A. T.; RYAN, P .D... PAST: Paleontological Statistics Software Package for Education and Data Analysis. Palaeontologia Electronica, v. 4, 9pp, 2001. Disponivel em < $\underline{\text { http://palaeo- }}$ electronica.org/2001_1/past/issue1_01.htm>. Acesso em 11 de junho de 2012.

HARDER, I. C. F.; RIBEIRO, R. C. S. ;TAVARES, A. R. Índices de área verde e cobertura vegetal para as praças do município de Vinhedo, SP. Revista Árvore, v. 30, n. 2, p. 277-282, 2006.

INSTITUTO FLORESTAL - Inventario Florestal da Vegetação Natural do Estado de São Paulo, São Paulo: Imprensa Oficial, Atlas, 200 p., 2005.

LIMA NETO, E. M. Índices Espaciais da Arborização Urbana em Áreas Verdes Públicas de Aracaju, Sergipe. 2008. (Monografia de Bacharelado em Engenharia Florestal) Universidade Federal de Sergipe (Núcleo de Engenharia Florestal/ UFS). São Cristóvão, Sergipe.

MAGURRAN, A. E. Ecological diversity and its measurement. Princeton: Princeton University Press, 1988.

MASCARÓ, J.; MASCARÓ, L. Vegetação urbana. 2 ed. Porto Alegre: Editora Mais Quatro, 2005.

MCPHERSON, E. G. Expenditures associated with conflicts between street tree root growth and hardscape in California, United States. Journal of Arboriculture, v. 26, n. 6, p. 289 - 297, 2000.

MENEGHETTI, G. I. P. Estudos de dois métodos de amostragem para inventário de arborização de ruas dos bairros da orla marítima do município de Santos - SP. 2003. 100p. Dissertação (Mestrado) - Escola Superior Agrícola "Luiz de Queiroz”, Piracicaba.

MILANO, M. S.; DALCIN, E. Arborização de vias públicas. Rio de Janeiro: Light, 2000.

MISSOURI BOTANICAL GARDEN. Tropicos. 2012. Disponível em http:// http://www.tropicos.org/. Acesso em 11 de junho de 2012.

PIVETTA, K. F. L.; SILVA FILHO, D. F. Boletim acadêmico: arborização urbana. Jaboticabal, 2002.

ROCHA, R. T.; LELES, P. S. S.; NETO, S. N. O. Arborização das vias públicas em Nova Iguaçu, RJ: o caso dos bairros Rancho Novo e Centro. Revista Árvore, v. 28, n. 4, p. 599-607, 2004.

SANTOS, E. Caracterização dendrológica e estética de 18 espécies arbóreas com potencial de uso em paisagismo e arborização urbana. 1994.146 p. Dissertação (Mestrado em Ciência Florestal) - Universidade Federal de Viçosa, Viçosa, 1994.

SILVA FILHO, D. F et al. Banco de dados recreacional para cadastro, avaliação e manejo de arborização em vias públicas. Revista Árvore, v. 26, n. 5, p. 629-642, 2002.

SILVA, L.F. Situação da arborização viária e proposta de espécies para os bairros Antônio Zanaga I e II, da cidade de Americana/SP. [Dissertação de Mestrado]. Escola Superior de Agricultura Luiz de Queiroz, Piracicaba, 2005. 80 p.

SHASHUA-BAR, L.; HOFFMAN, M. E. Vegetation as a climatic component in the design of an urban street: an empirical model for predicting the cooling effect of urban green areas with trees. Ecology and Builings, v. 31, p. 221-235, 2000.

THE PLANT LIST. Version 1. 2010. Disponível em http://www.theplantlist.org/ . Acesso em 11 de junho de 2012.

VELASCO, G. D. N. Arborização viária X sistema de distribuição de energia elétrica: avaliação dos custos, estudo das podas e levantamento de problemas fitotécnicos. 2003. 94 p.Dissertação (Mestrado em Fitotecnia) - Escola Superior de Agricultura “Luiz de Queiroz”, Universidade de São Paulo, Piracicaba, 2003.

VELASCO, G. D. N.; LIMA, A. M. L. P.; COUTO, H. T. Z. Análise comparativa dos custos de diferentes redes de distribuição de energia elétrica no contexto da arborização urbana. Revista Árvore, v. 30. n. 4, p. 679-686, 2006.

DIVERSIDADE, FITOSSANIDADE E ADEQUAÇÃO DA... 